\title{
Haemolysis of human erythrocytes by pentachlorophenol and its suppression by albumin
}

\author{
Hideki Igisu
}

Pentachlorophenol (PCP), a potent and inexpensive biocide, has been used widely, especially for wood preservation. Because of its extensive use, there is concern about the possible health hazards caused by PCP. Cases of severe PCP intoxication have been described, some fatal. At least one case of haemolytic anaemia associated with PCP intoxication has been found ${ }^{1}$ but little is known about the effects of PCP on erythrocytes.

\section{Methods}

Pentachlorophenol and $\gamma$-globulin (from human serum) were purchased from Sigma (St Louis, MO) and human serum albumin from Chemical Dynamic Corporation (South Plainfield, NJ). Blood was obtained from healthy males. The erythrocyte suspension (packed cell volume $4.5 \%$ ) and the membranes were prepared as described. ${ }^{2}$

The PCP was first dissolved in ethanol. The reaction mixture for the determination of haemolysis contained $0.68 \mathrm{ml}$ isotonic buffer $(30 \mathrm{mM}$ Tris $\mathrm{HCl}$, pH $7 \cdot 4$, with $120 \mathrm{mM} \mathrm{NaCl}, 5 \mathrm{mM} \mathrm{KCl}$, and $2 \mathrm{mM} \mathrm{MgCl}$ ) and $0.02 \mathrm{ml}$ ethanol with or without PCP. The incubation and the calculation of haemolysis were as reported previously. ${ }^{3}$

To examine binding of PCP, the concentrations in solutions were estimated spectrophotometrically. ${ }^{4}$ The membrane suspension (in $10 \mathrm{mM}$ Tris $\mathrm{HCl} \mathrm{pH} \mathrm{7.4,4} \mathrm{mg} \mathrm{protein} / \mathrm{ml}, 0.25 \mathrm{ml}$ ) was mixed with $0.25 \mathrm{ml} 0.1 \mathrm{M}$ potassium phosphate buffer $\mathrm{pH} 7.4$ and $0.01 \mathrm{ml}$ ethanol with or without PCP. After incubation at $37^{\circ} \mathrm{C}$ for 30 minutes, the mixture was centrifuged at $15000 \mathrm{~g}$ for $30 \mathrm{~min}$ utes. The supernatant was diluted five times with the phosphate buffer and the absorbance at $320 \mathrm{~nm}$ was measured (free PCP). The PCP solution (in ethanol) was diluted in the same way and the absorbance was measured (total PCP).

In the ultrafiltration study, the isotonic buffer

Department of Environmental Toxicology, Institute of Industrial Ecological Sciences, University of Occupational and Environmental Health, Kitakyushu 807, Japan H Igisu

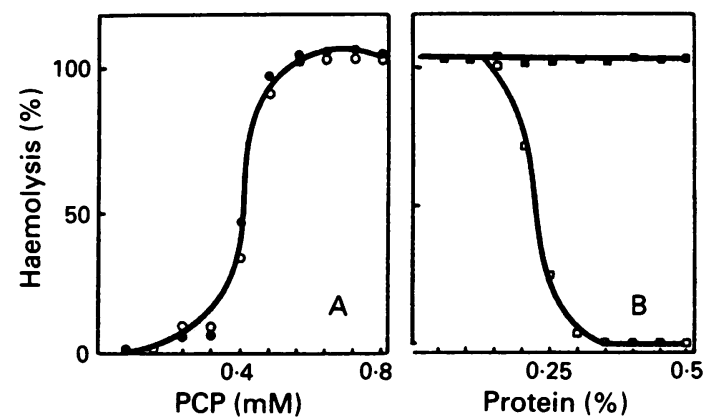

Figure 1 (A) Haemolysis caused by pentachlorophenol (PCP). Washed erythrocytes were incubated at $37^{\circ} \mathrm{C}$ for two hours with $P C P(0.08-0.8 \mathrm{mM})$ in the presence $(\mathrm{O})$ and absence (O) of $5 \mathrm{mM}$ glucose. (B) Effects of albumin ( $\square$ ) and $\gamma$-globulin ( $)$ on PCP induced haemolysis. Washed erythrocytes were incubated with $0.8 \mathrm{mMPCP}$ and various amounts of the protein (0.05-0.5\%). The incubation was done at $37^{\circ} \mathrm{C}$ for one hour. Each line was examined with a logistic regression analysis; $y=1 /(1+\exp (-a-b x))$ where $x$ was the dose and $a=-12.5(0),-13.0(0)$, $11 \cdot 5$ ( $\square$ ), and $3.7(\square), b=1 \cdot 2$ (O), $1 \cdot 3(\mathrm{O}),-0 \cdot 2$ $(\square)$, and 0.0 (口). In every case the results fitted well with the estimation ( $p<0.01, F$ test).

$(1.96 \mathrm{ml})$ containing albumin or $\gamma$-globulin was mixed with $0.04 \mathrm{ml}$ ethanol containing $10 \mathrm{mM}$ PCP, and transferred to Ultracent-10 (Tosoh, Tokyo). After centrifugation at $1000 \mathrm{~g}$ for 40 minutes, PCP in the filtrate was measured. All measurements on haemolysis and protein binding were done in duplicate, and each experiment was carried out at least twice.

\section{Results}

When PCP was added to the reaction mixture, haemolysis was seen (fig 1A). Presence of glucose ( $5 \mathrm{mM}$ ) did not affect haemolysis. On the other hand, haemolysis (by $0.8 \mathrm{mM}$ PCP) was completely abolished by albumin (fig 1B). $\gamma$-Globulin, however, did not suppress the haemolysis. $(\gamma-$ Globulin itself did not haemolyse the cells.)

The concentration of PCP in the supernatant after sedimentation of the erythrocyte membrane decreased as the amount of membrane increased. When the concentration of PCP was varied, a clear 


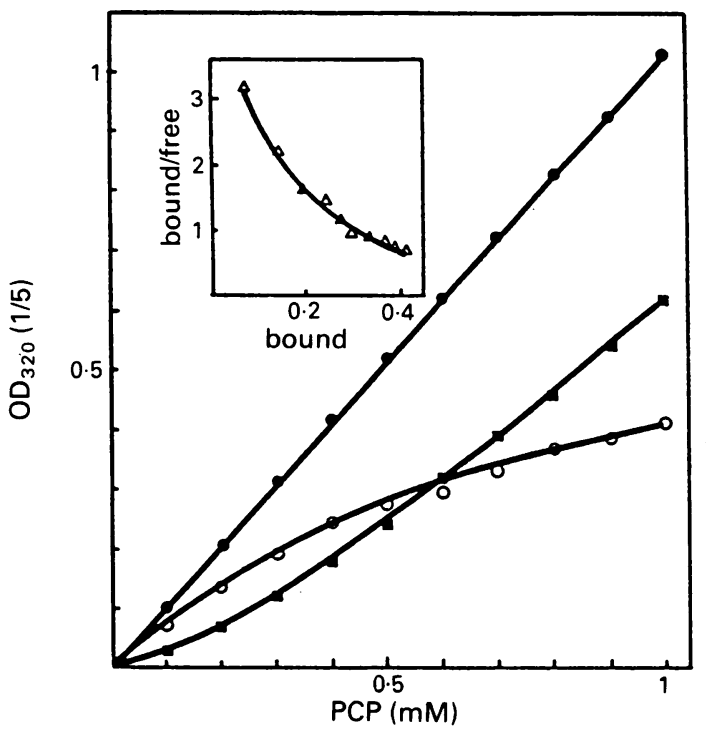

Figure 2 Absorbance (320 nm) of the PCP solution (O) (total PCP) and that of the supernatant after sedimentation of the membrane ( $\square$ ) (free PCP). Solutions were diluted five times before spectrophotometric measurement. The calculated difference (O) (bound PCP) is also shown. The Scatchard plot for the binding of PCP to the membrane is shown in the inset. Coefficients in logistic regression analysis (see legend for fig 1) were: $a=-3.01$ (日), -2.02 (0), $b=3.57$ (日), and $1.78(O)$. The results fitted well with the estimation $(p<0.01, F$ test). The Scatchard plot fitted well $(r=0.983)$ with a second order model on a polynominal regression analysis consistent with a curved line.

linear relation was seen between the concentration and the absorbance at $320 \mathrm{~nm}$ (fig 2). Taking the difference of the total and free PCP as the bound PCP, Scatchard analysis produced a curve (fig 2).

In the ultrafiltration study, the concentration of PCP in the filtrate decreased as the concentration of albumin in the mixture increased. The presence of $\gamma$-globulin did not alter the PCP concentration in the filtrate (data not shown).

\section{Discussion}

The results show that PCP can haemolyse human erythrocytes and erythrocyte membranes can bind PCP. Moreover, PCP decreased the fluidity of purified plasma membrane. ${ }^{5}$ Thus it seems that PCP haemolyses human erythrocytes through its interaction with the membrane.
A curved plot was obtained from Scatchard analysis, suggesting that the erythrocyte membrane has multiple binding sites for PCP with different affinities. Hence, it is possible that PCP attacks more than one component of the membrane.

Albumin could completely suppress the PCP induced haemolysis, whereas $\gamma$-globulin could not. The results of the ultrafiltration study indicated that albumin (but not $\gamma$-globulin) bound PCP. Weinbach et al ${ }^{6}$ reported that albumin could restore mitochondrial function impaired by PCP. Thus albumin can potently counteract the effects of PCP and this seems due to its capacity to bind PCP.

Because human serum contains more than $3 \%$ of albumin, it seems reasonable that haemolytic anaemia has only rarely been seen in PCP intoxication $^{1}$ and that exchange blood transfusion showed a dramatic effect in patients severely intoxicated with PCP. ${ }^{7}$ It should be noted, however, that haemolytic anaemia might be induced if the equilibrium of PCP between albumin and erythrocytes should be altered.

I thank Professor M Ikeda for his help with statistical analyses.

Requests for reprints to: Hideki Igisu, $M D$, Department of Environmental Toxicology, University of Occupational and Environmental Health, Kitakyushu 807, Japan.

1 Hassan AB, Seligmann H, Bassan HM. Intravascular haemolysis induced by pentachlorophenol. BMF 1985;291:21-2.

2 Igisu H, Mawatari S. Effect of propranolol on ATP in human erythrocytes-comparison with ouabain. Biochem Med $1980 ; 23: 70-5$.

3 Igisu H, Hamasaki N, Ito A, Ou W. Inhibition of cytochrome c oxidase and hemolysis caused by lysosphingolipids. Lipids 1988;23:345-8.

4 Bowen WJ, Martin HL, Jacobus WE. Binding of pentachlorophenol by actomyosin. Biochemistry 1965;4:1936-41.

5 Duxbury CL, Thompson JE. Pentachlorophenol alters the molecular organization of membranes in mammalian cells. Arch Environ Contam Toxicol 1987;16:367-73.

6 Weinbach EC, Sheffield H, Garbus J. Restoration of oxidative phosphorylation and morphological integrity to swollen, uncoupled rat liver mitochondria. Proc Natl Acad Sci USA 1963;50:561-8.

7 Robson AM, Kissane JM, Elvick NH, Pundavela L. Pentachlorophenol poisoning in a nursery for newborn infants. I. Clinical features and treatment. $\mathcal{f}$ Pediatr 1969;75:309-16.

Accepted 6 July 1992 